\title{
PERCEPÇÃO DA VIOLÊNCIA DOMÉSTICA CONTRA MULHER COM COMPROMETIMENTO FÍSICO E/OU NEUROLÓGICO ${ }^{8}$. \\ Perception of domestic violence against women with physical and/ or neurological impairment. http://dx.doi.org/10.21116/2019.4
}

\section{SOUZA, Amanda Cristina}

Centro Universitário de Jaguariúna - UNIFAJ

OLIVEIRA, Dalita da Conceição

Centro Universitário de Jaguariúna - UNIFAJ

\section{ELLIS, Elaine Regina Donato}

Centro Universitário de Jaguariúna - UNIFAJ

\section{AUDI, Celene Aparecida Ferrari \\ Centro Universitário de Jaguariúna - UNIFAJ}

Resumo: Introdução: A violência contra a mulher é reconhecida como grave problema de saúde pública. É um obstáculo ao alcance dos objetivos de igualdade, desenvolvimento e paz, ainda é uma ocorrência que viola os direitos humanos. Objetivo: avaliar a percepção da violência doméstica por mulheres que apresentem comprometimento físico e/ou neurológico. Método: Foram incluídas mulheres que com alguma deficiência física e/ou neurológica que eram acompanhadas na Clínica-escola de Fisioterapia no Centro Universitário. Resultados: Oito mulheres apresentavam condições clínicas que possibilitaram participar do grupo focal. Resultados: Idade em média 65,5 anos, $62 \%$ casadas, cor branca, religião evangélica, não trabalhavam e tinham baixa escolaridade. Em relação à violência, $23 \%$ das mulheres entrevistadas relataram terem sofrido violência física e psicológica antes da deficiência física/ neurológica. Após a deficiência, $46 \%$ do grupo relatou sofrer violência psicológica e $8 \%$ violência física. Três categorias emergiram após análise de conteúdo: A) Não aceitação pelo marido e outros familiares em relação à doença. B) Dificuldade em se expressar pode levar a condição de submissão. C) A prevenção da violência contra a mulher deve começar na infância. Conclusão: profissionais de saúde devem estar preparados para atuar nos níveis de prevenção da história natural da saúde e da doença.

Palavras chaves Pessoas com Deficiência. Violência Contra a Mulher. Pesquisa Qualitativa.

Abstract: Introduction: Violence against women is recognized as a serious public health problem. It is an obstacle to achieving the goals of equality, development and peace, yet it is a violation of human rights. Objective: to evaluate the perception of domestic violence by women who present physical and / or neurological impairment. Method: We included women with some physical and / or neurological disabilities who were followed up at the ClinicSchool of Physical Therapy at the University Center. Results: Eight women had

\footnotetext{
${ }^{8}$ Trabalho apresentado no 18을 Congresso Nacional de Iniciação Científica - CONIC SEMESP em 2018.
} 
clinical conditions that allowed them to participate in the focal group. Results: Age on average 65.5 years, $62 \%$ married, white, evangelical religion, did not work and had low schooling. Regarding violence, $23 \%$ of the women interviewed reported having suffered physical and psychological violence before their physical / neurological deficiency. After the disability, $46 \%$ of the group reported suffering psychological violence and $8 \%$ physical violence. Three categories emerged after content analysis: A) Non-acceptance by husband and other family members regarding the disease. B) Difficulty in expressing yourself can lead to submission. C) Prevention of violence against women should begin in childhood. Conclusion: health professionals should be prepared to act at the prevention levels of the natural history of health and disease.

Key-words: People with Disabilities. Violence Against Women. Qualitative research

\section{INTRODUÇÃO}

A violência contra a mulher trata-se de qualquer ação violenta baseado no gênero, que tenha como resultado, dano físico, sexual, psicológico ou sofrimento para a mulher, incluindo ameaça, a coerção ou privação da liberdade em ambiente privado ou público. Esse fenômeno também pode ser classificado como violência de gênero ou violência doméstica e consiste em situações complexas, que abrange vários tipos de ações e tem suas fundações nas relações sociais, culturais, econômicos e políticos, (SILVA e OLIVEIRA, 2014, p. 3524).

Segundo a OMS, em relatório sobre a resposta a violência por parceiro íntimo e a violência sexual contra as mulheres, em 2011, diz que a violência contra as mulheres é um dos principais problemas de saúde pública e direitos humanos. Tem como resultado o prejuízo para a saúde física e mental, a curto e longo prazo.

Mesmo sem nomear, a maioria das mulheres reconhece a vivência da violência como algo que não é certo, que traz sofrimento e não desejam tal situação; no entanto, a contradição foi observada na representação da violência como parte da vida (Schraiber et al.,2003)., o que pode ser entendido como um dos desfechos subjetivos que levam a perpetuação da violência nas relações atuais, (Hermel e Drehmer - 2013).

Devido ao fato de apresentar um comprometimento, esse grupo tornase mais vulnerável as violências domésticas. Mesmo estando respaldadas pela Constituição Federal e diversa Planos de Ações do governo, não se encontra 
dados suficientes onde mostra quais são as violências sofridas pelas mulheres com limitações físicas e/ou neurológicas.

O objetivo do desenvolvimento do trabalho é avaliar violências domésticas sofridas pelas mulheres com comprometimento físico e/ou neurológico e o impacto que ocasionou na vida das mesmas.

\section{MÉTODO}

Seleção das Participantes:

Foram incluídas mulheres que apresentavam alguma deficiência física e/ou neurológica que eram acompanhadas na Clínica de Fisioterapia localizada na línica-escola (Interclínicas) de um Centro Universitário no interior do estado de São Paulo. As mulheres selecionadas apresentavam condições clínicas, emocionais e intelectuais mínimas para submeter-se a entrevista e ter entendimento do que se perguntava, assim como, elaboração das respostas.

Após contato e explicação do objetivo e como seria realizada a pesquisa em havendo a aceitação as mulheres assinavam o Termo de Consentimento Livre e Esclarecido (TCLE). Como critério de exclusão, foram consideradas mulheres que não desejaram participar da pesquisa e aquelas que não tinham condições de manter um diálogo por condições relacionadas às sequelas da patologia. A coleta de dados da pesquisa iniciou no mês de novembro de 2017 e finalizada em maio de 2018.

Método Clínico-Qualitativo e Entrevista Semidirigida de Questões Abertas: Adequar o enfoque ao objeto de estudo, a escolha de uma estratégia de pesquisa revela a arte de um pesquisador em adaptar um modelo a uma situação específica (BARDIN, 2011). Em nossa pesquisa buscamos através do relato das mulheres que além de estarem com algum comprometimento físico e/ou neurológico sofreram violência doméstica (psicológica, física e sexual), revelando a sua percepção, sentidos e significados da violência doméstica.

A origem de um método com essa base é a postura ou atitude clínica de pesquisador que se valha dos atributos de sua prática clínico-assistencial. $A$ atitude clínica que requer de um pesquisador na área da saúde que aborde indivíduos humanos como "objetos" de estudo é assim definido por TURATO 
(2003):

"É a postura de acolhida do sofrimento existência e emocional do indivíduo alvo dos estudos do pesquisador, assumida por este profissional, que assim inclina sua postura de escuta, seu olhar e suas múltiplas e interligadas sensibilidades, interagida com seus conhecimentos teóricos da metodologia de investigação, em direção àquela pessoa a quem melhor quer conhecer e compreender cientificamente, empreendendo de forma sistematizada uma pesquisa dos fenômenos como percebidos por este indivíduo, e sendo primitivamente movido pelo desejo de ajuda a quem sofre. (TURATO, 2003, p.240)".

No primeiro momento foi utilizado para entrevista questionário com questões fechadas que tratavam das condições sociodemográficas (dados de identificação pessoal da entrevistada). Em segundo momento, buscou conhecer as vivências, a percepção o significado da violência doméstica após a limitação física e/ou neurológica e como isto alterou suas atividades e principalmente seus relacionamentos, para este momento da pesquisa anotamos e gravamos as falas dessas mulheres; na terceira e última parte, ficam reservados para dados suplementares, que forem oportunos e relevantes para a pesquisa. O diagnóstico médico das limitações física e/ou neurológicas foi verificado no prontuário das entrevistadas.

Nas pesquisas qualitativas caracterizam-se, por sua vez, entre outras características, por explorarem seu objeto de estudo de forma naturalística, abordando em seu setting natural, (BOGDAN e BIKLEN, 1994).

O tamanho amostral, a formação do grupo das participantes para o presente estudo foi segundo amostragem por saturação, isto é, o pesquisador fechou o grupo quando, após informações coletadas com certo número de sujeitos, novas entrevistas passaram a apresentar uma quantidade de repetições nos conteúdos. Assim, o grupo respeitou a homogeneidade interna ampla, definida para todos os indivíduos que o compõem, no caso mulheres vitimadas pela violência doméstica (psicológica, física, sexual com algum comprometimento físico e/ou neurológico). O pesquisador, entendendo que novas falas passam a ter acréscimos irrelevantes, em vista dos objetivos inicialmente propostos para pesquisa, decide encerrar a amostra.

Segundo Morse e Field (1995) enfatizam que o critério da adequação 
na pesquisa qualitativa se refere à quantidade de dados coletados e ele é alcançado quando ocorre à saturação e então as variações estariam representadas e compreendidas. Para Bogdan e Biklen (1994), por sua vez, lembram-nos que os pesquisadores qualitativos aferem o momento em que devem terminar a coleta, quando se atinge a saturação dos dados: o momento da atividade da coleta de dados no qual as informações que então se obtém tornam-se redundantes.

Tratamento dos dados:

Os dados foram coletados e tratados através da chamada Análise Qualitativos de Conteúdo, destacando-se a etapa denominada processo de categorização, após leitura e releituras flutuantes do corpus (conjunto de todas as entrevistas transcritas na íntegra).

Segundo Bardin (2011), este processo preconiza uma operação de classificação dos elementos constituídos de um conjunto de dados levantados, primeiramente por diferenciação e, em seguida por um reagrupamento conforme o gênero. Tal tópico é constituído por uma analogia entre os elementos com critérios definíveis durante o momento de diferenciação. Em outras palavras, serão reagrupados trechos de falas, contidos nas respostas aos tópicos tratados, segundo aqueles trechos apresentem falas em comum.

Com a apreciação do conjunto do material levantado - o corpus - é que se consolidará tal categorização, pois dados surgidos poderão ser considerados de consistência para serem contemplados com uma discussão relevante para os objetivos propostos na pesquisa.

Referenciais para discussão dos resultados:

Foram realizados à luz de um quadro eclético de referenciais teóricos habitualmente usados nas áreas disciplinares da psicologia aplicada à saúde, documentos oficiais sobre o tema estudado e outras pesquisas realizadas.

A apresentação dos resultados da pesquisa clínico-qualitativa deve ser descrita e ocorre conjuntamente com sua discussão na versão redigida do trabalho, assim como, apresentação dos resultados nos escritos finais da pesquisa deve incluir citações literais dos entrevistados, a título de ilustração, devendo o autor, no entanto, ser parcimonioso no número das ilustrações. 
(TURATO, 2003).

Para a etapa da discussão/interpretação do material obtido, a concepção da pesquisa clínico-qualitativa acompanha as exigências naturais da interdisciplinaridade. Como requerem as características metodológicas das pesquisas qualitativas nas Ciências do Homem, a discussão de nossos achados poderá ocorrer com outras teorias de vertentes psico-socio-culturais que joguem luz no entendimento dos resultados do presente projeto.

\section{RESULTADOS E DISCUSSÃO}

As mulheres tinham em média 65,5 anos de idade, sendo $62 \%$ casada, cor auto relatada branca e religião evangélica, 92\% delas não trabalhavam e $46 \%$ delas tinham o ensino médio incompleto. Em relação à violência antes da deficiência físico-neurológica $23 \%$ relataram sofre violência psicológica e física, depois que apresentaram a deficiência físico-neurológica $46 \%$ relatou sofre violência psicológica e $8 \%$ violência física. Esta violência começou cedo na vida dessas mulheres, antes dos 15 anos de idade $23 \%$ relataram violência física e 15\% violência sexual. Quanto ao diagnóstico médico das patologias foram pesquisados nos prontuários das participantes e as patologias, segundo CID 10: Neuropatia hereditária motora e sensorial; Sequelas de doenças cerebrovasculares; Atrofias sistêmicas que afetam principalmente o Sistema Nervoso Central e Distrofia Muscular progressiva.

A pesquisa qualitativa preocupa-se com uma realidade que não pode ser quantificada, respondendo a questões muito particulares, trabalhando um universo de significados, crenças, valores e que correspondem a um espaço mais profundo das relações, dos fenômenos que não podem ser reduzidos à operacionalização de variáveis, (DESLANDE,1994).

Durante o desenvolvimento do grupo focal percebia-se que as opiniões, em geral decorriam de suas vivências pessoais em família e na sociedade. Foram apresentadas pelas mulheres momentos importante e individual de sua vida tomando como objeto de estudo as experiências singulares experimentadas por cada mulher e nelas destacadas os aspectos relacionados à violência doméstica. Mesmo tendo em vista que Denzin (1999) refere que a História da Vida apresentada por uma pessoa, um grupo, uma organização, vem permeada por experiências e definições a partir da maneira 
como a experiência é percebida ou interpretada.

As opiniões e ideias, acerca do tema fluíram com muita naturalidade e sem constrangimentos, mostrando o desejo dessas mulheres em expor seus problemas e suas formas de lidar com eles. O que está de acordo com Estudo da OMS (2005), sobre violência contra a mulher, realizado em 10 países, ao relatar que em todos esses países as mulheres não só estiveram dispostas a falar sobre suas experiências ao sofrerem violência, como, também se demonstravam agradecidas pela oportunidade Ihes oferecida, de poderem falar para pessoas empáticas, sem sofrem julgamentos ou críticas.

Considerando as categorias temáticas emergidas das falas das mulheres a seguir discutidas podemos fazer algumas inferências e considerações, contextualizadas aos objetivos do estudo e tendo em vista a relevância da violência doméstica que incide sobre a mulher de maneira oculta e perversa, frequentemente, oriunda de seus próprios parceiros e parentes.

Fundamentalmente lembrando ser ela um ser humano e cidadã, sobrecarregada de papéis sociais e responsabilidades políticas na vida.

Nessas categorias, descritas no trabalho está o reflexo da relevância dos fenômenos psicológicos, clínicos e sociais decorrentes das vivências relatadas pelas mulheres que, podem ser generalizadas a outras circunstâncias semelhantes (RODRIGUES E LEOPARDI, 1999).

Categoria Temática no1: Não aceitação familiar perante a deficiência. Durante o estudo, pode-se observar a não aceitação da família frente à Mulher com deficiência. Em realização de grupo focal, foi possível observar manifestações diversas referentes à negação.

"Violência é quando você é rejeitada"

"Há às vezes eles acham que a gente é incapaz, normalmente vem do marido né. Mas já mostrei para ele que eu sou capaz".

"Eu fazia muitas coisas, e às vezes meu marido não aceita eu ter ficado assim, mas eu vou fazer o que, não escolhi ficar assim".

"Meu marido não aceita que o que eu tenho é genético, minha idade é de 40 anos, mas eu não tenho a agilidade para minha idade, e para ele é difícil aceitar. Às vezes ele "escorrega no tomate" como expressão para dizer que a ofende". 
"Eles casam com uma pessoa perfeita e normal, e depois as pessoas vão tendo problemas, o meu marido é 13 anos mais velho que eu, e ele não aceita eu ser mais limitada que ele, sendo que ele é mais velho, não entende que a doença me deixou assim."

"Eles andam na frente e não respeitam o nosso tempo..."

Segundo Borges (2003) a mulher que adoece e se torna dependente desloca-se do lugar de sujeito das operações do cotidiano familiar (aquela que cuida de tudo e de todos, que administra e organiza a dinâmica familiar) para um lugar de objetos de cuidado. A negação do esposo frente o adoecimento e mudança do cotidiano os levam a desenvolver violências psicológicas em todos os casos relatados.

Para Hermel e Drehmer (2013), a família é considerada um microssistema, já que ela possui um padrão de funcionamento, de papéis e de relacionamentos que estão associados aos comportamentos e ás interações em determinados contextos.

Baseado nessa referencial tem-se a família como um sistema integrado que opera para manter o equilíbrio nos diferentes contextos nos quais lá se insere. Com isso, espera-se que o indivíduo encontre na família condições para subsidiar seu desenvolvimento saudável. Contudo, essa ideia tem sido contraproposta pela dimensão e pelos problemas cada vez maiores da violência familiar, considerada pelo Ministério da Saúde, (BRASIL, 2002).

Categoria Temática no 2: A dificuldade em se expressar pode levar condição de submissão.

Os relatos apontavam para: baixa autoestima, menos-valia do ser mulher frente às condutas masculinas dentro do ambiente familiar, sendo destacada, por elas, a força masculina como um fator a subjugá-las.

"eu já nem converso por causa disso, porque eu sei que o que eu falar ele não vai entender, então eu não converso eu já fico quieta, no meu canto. Ele é muito nervoso, palito quente, qualquer coisinha que você falar se ele achar que vai contrai-lo, já estoura, ai eu fico calada".

“... eu procuro ficar quieta, a violência começa em casa, qualquer coisinha já quer bater..."

"Ele não me deixa acabar de falar e já discuti..." 
Os episódios de agressão praticados contra a mulher são prejudiciais à sua saúde, não pela fragilidade da condição feminina, mas principalmente porque a violência é o próprio parceiro íntimo ou um familiar próximo. A desigualdade de forças, onde a mulher dificilmente conseguiria se defender das agressões levam as mulheres a ficarem sem respostas evitando, assim, a violência psicológica por meio de insultos, xingamentos e ofensas, obviamente não era esta a atitude que esperava do seu parceiro e/ou de seu familiar mais próximo. Essa violência pode afetar de forma significativa a integridade biopsicossocial da mulher, gerando uma série de sintomatologias e transtornos do desenvolvimento físico e psicológico agravando sua condição de saúde que já se encontra vulnerável, (SANTOS, 2017).

Esta condição pode ser considerada como dupla vulnerabilidade que além da mulher apresentar uma deficiência física ela está sobre condições de violência, em sua maioria elas não se reconhecem como cidadãs, se sentem inferiorizadas, menosprezadas, rejeitadas e por vezes inconscientemente se culpam por estarem nesta situação, gera-se a cessão de liberdade, onde as mulheres perdem sua voz, por medo, para evitar conflitos, ou porque acredita que o agressor tem poder sobre a mesma. Esta sensação acaba paralisandoas em uma condição onde a violência ocorre sem ser exposta para que possa encontrar ajuda as mulheres acabam se acomodando nessa situação, remetendo que a desigualdade de poder no campo da deficiência jamais será resolvida, (NICOLAU, 2013; DINIZ 2003).

Categoria Temática no 3: A prevenção da violência deve começar na infância:

"eu via meu pai batendo em nós, mas eu não entendia como uma agressão, achava que era brincadeira";

" meu pai agredia muito minha mãe".

" se a mulher e o marido discutem muito perto da criança, ou a mulher sofre violência perto da criança, automaticamente quando ele crescer vai fazer a mesma coisa"

"meu marido era quando ele bebia. Ele bebia muito, era muito agressivo"; "meu marido bebia, fazia eu e meus filhos correr pra se esconder". Eu já passei muito aperto." 
“... sabe o que eu acho mesmo que todo mundo já devia conversar com as crianças desde pequenos sobre esta questão de violência. Todo mundo a família, a escola em todos os lugares, aí as crianças iam crescer sabendo que não é para bater, xingar e tudo mais essas coisas".

Estudos apontam que ao nascer, a criança inscreve-se em registros biológicos, jurídicos e psíquicos. O processo de filiação, enquanto processo psíquico vincular, se dá por mecanismos e motivos inconscientes que acontecem via transmissão intersubjetiva. Como forma de funcionamento psíquico originado nas primeiras relações objeta, o vínculo estabelece um laço primordial. (CORREA, 2003; Neves, Gomes, Vidal, RJ, 2014), sendo a família, considerada um grupo primordial no âmbito do desenvolvimento de sujeitos psíquicos e singulares, (Neves, Gomes, Vidal, RJ, 2014).

Está comprovado na literatura nacional e internacional que as situações de violência vivenciadas pelas crianças e adolescentes repercutem por todo ciclo de vida podendo perdurar e reproduzir na vida adulta. Os traumas que excedem a capacidade de compreensão e elaboração da criança e do adolescente podem ter efeitos imediatos ou tardios, que repercutirão no seu modo primário de pensar e de agir, bem como na sua capacidade de enfrentar outras situações de dificuldade ou estresse para o resto de suas vidas, (DOWD, 2017; Pfeiffer, Rosário, Cat Rev Paul Pediatr, 2011; AUDI, 2008; WATTS, 2002). Podem apresentar problemas de relacionamento, com vínculos afetivos, frágeis e inseguros, dificuldade em lidar com os próprios sentimentos. (SCHEK, SILVA, LACHARITÉ, BUENO, RS, 2016), em geral as mulheres que vivenciaram violência doméstica relacionavam as agressões aos momentos em que os companheiros estavam alcoolizados, tirando deles a responsabilidade sobre o ocorrido, com a justificativa de que estavam sob o efeito do álcool. (Hermel, Drehmer, Curitiba, 2012).

A forma de cuidado e prevenção da violência nos distintos ciclos de vida se dá por profissionais multidisciplinares, desde as escolas até as unidades básicas de saúde, perpassando pela família e conscientização da população, assim como, contemplar os agressores espaços de reabilitação, dando-lhe assim, a oportunidade de refletir e, principalmente, mudar seu comportamento, (SCHEK, SILVA, LACHARITÉ, BUENO, RS, 2016). É 
imprescindível o fortalecimento de políticas públicas através de intervenções efetivas, buscando soluções para o enfrentamento desse fenômeno, em todos os seguimentos da sociedade, (MONTEIRO, 2018).

\section{CONSIDERAÇÕES FINAIS}

Um longo percurso, pelas pesquisadoras, foi realizado até que pudéssemos encontrar essas mulheres. A violência doméstica, neste caso, também é invisível aos serviços que deveriam ter portas abertas para o atendimento, acolhimento e até mesmo conhecimento sobre as prevalências de mulheres com deficiências físicas e/ou neurológicas, fato este que dificultou a realização desta pesquisa.

Os profissionais da rede de atendimento dessas mulheres devem estar qualificados para atuar junto a essa população, garantindo atendimento humanizado e efetivação dos direitos, o qual possibilita resgatar a dignidade humana tão fragilizada dessas mulheres.

\section{REFERÊNCIAS}

AUDI, Celene Aparecida Ferrari, CORRÊA, Ana M Segall, SANTIAGO, Silvia M, ANDRADE, Maria da Graça G, ESCAMILLA, Rafael Pérez. Violência doméstica na gravidez: prevalência e fatores associados. Rev. Saúde Pública, São Paulo, Outubro de 2008, v. 42, n. 5, p. < http://dx.doi.org/10.1590/S003489102008005000041 . >Acesso: 24 de Agosto 2018.

BOGDAN, R. C.;BIKLEN, S. K. Investigação Qualitativa em Educação: uma introdução à teoria e aos métodos. Porto -Portugal. Porto Editora, 1994. < https://docente.ifrn.edu.br/albinonunes/disciplinas/pesquisa-emensino/investigacao-qualitativa>. Acesso: 24 agosto 2018

BRASIL. Secretaria de Direitos Humanos - Convenção sobre os Direitos das Pessoas com Deficiência: Protocolo Facultativo à Convenção sobre os Direitos das Pessoas com Deficiência: Decreto Legislativo no 186, de 09 de julho de 2008: Decreto no 6.949, de 25 de agosto de 2009. Brasília, 2010. < http://www.pessoacomdeficiencia.gov.br/app/sites/default/files/publicacoes/convenc aopessoascomdeficiencia.pdf>. Acesso: 24 de agosto 2018

BORGES, Claudia Fernandes; Dependência e morte da "mãe de família": a sociedade familiar e comunitária nos cuidados com a paciente de esclerose lateral amiotrófica. Psicologia em estudo. Maringa, v.8, num. esp.,p. 21-29, 2003. < http://www.scielo.br/pdf/\%0D/pe/v8nspe/v8nesa04.pdf>. Acesso: 24 de agosto 2018

COMPILED, Beusenberg By M, ORLEY and J. A user's guide to the self reporting questionnaire. Disponível em:

<http://apps.who.int/iris/bitstream/10665/61113/1/WHO_MNH_PSF_94.8.pdf;> 
Acesso: 28 de agosto 2018.

Diniz D. Modelo social da deficiência: a crítica feminista. Brasília: Letraslivres; 2003. (Série Anis, n. 28). <

http://repositorio.unb.br/bitstream/10482/15250/1/ARTIGO_ModeloSocialDeficiencia. pdf>. Acesso: 24 de agosto 2018

Diversidade da Mulher com Deficiência.

http://www.spm.gov.br/assuntos/diversidade-das-mulheres/com-deficiencia>.

Acesso: 28 de agosto de 2018.

DOWD MD. Intimate Partner Violence and Pediatric Practice. Pediatric Annals.

2017;46(12):e438-e440. < https://doi.org/10.3928/19382359-20171127- 01.>.

Acesso: 28 de agosto de 2018

HERMEL, Júlia Schneider; DREHMER, Luciana Balestrin Redivo. Repercussões da violência intrafamiliar: Um estudo com mulheres em acompanhamento psicológico. Psicologia argumento - dossiê. Curitiba, v.13, n. 74, p. 437-446, jul/set. 2013. < https://periodicos.pucpr.br/index.php/psicologia

argumento/article/view/20395>. Acesso: 28 de Agosto de 2018

MONTEIRO, Ana Cláudia de Souza et al . Olhares maternos acerca da violência contra a criança: constituindo significados. Rev. Bras. Enfermagem., v. 71, n. 1, p. 34-39, fev. 2018. < http://dx.doi.org/10.1590/00347167-2016-0568. >. Acesso 24 ago. 2018

MORSE, J.M. \& FIELD, P.A. Qualitative research methods for health professionals. Thousands Oaks, Sage, 1995. 254p.

$<$ https://www.scielosp.org/scielo.php?pid=S003489102005000300025\&script=sci_ar ttext\&tlng=en> Acesso: 24 de Agosto 2018

NICOLAU, Stella Maris; SCHRAIBER, Lilia Blima; AYRES, José Ricardo de Carvalho Mesquita. Mulheres com deficiência e sua dupla vulnerabilidade: contribuições para a construção da integralidade em saúde. Ciênc. saúde coletiva, Rio de Janeiro, v. 18, n. 3, p. 863-872, Mar.

2013.<http://dx.doi.org/10.1590/S1413-81232013000300032.>Acesso: 25 agosto 2018

Resposta à violência por parceiro íntimo e a violência sexual contra as mulheres. Disponível em:

http://apps.who.int/iris/bitstream/10665/44350/3/9789275716359_por.pdf acessado em 28 de agosto de 2018.

SILVA, L.E.L.; OLIVEIRA, M. L. C. Violência contra a mulher: revisão sistemática da produção cientifica nacional no período de 2009 a 2013. Ciência \& Saúde Coletiva. Número: 20, pág. 3523 - 3532, 2013.

<http://www.scielo.br/scielo.php?pid=S141381232015001103523\&script=sci_abstra ct\&tlng=pt>. Acesso: 24 agosto 2018

Tate DG, Weston $\mathrm{NH}$. Women with disabilities: an international perspective. Rehabil Lit. < https://www.researchgate.net/profile/Denise_Tate/ publication/234755485_Women_and_Disabilities_An_International_Perspective /links/56f5388908ae7c1 fda2ee110/Women-and-Disabilities-An-International-

Perspective.pdf> Acesso: 24 agosto 2018 
Santos DF; Castro DS; Lima EFA; et al. Percepção de mulheres acerca da violência vivenciada. Rev Fund Care Online. 2017 jan/mar; 9(1):193-199. DOI: <http://dx.doi.org/10.9789/2175-5361.2017.v9i1.193-199.>. Acesso: 24 de Agosto 2018

TURATO, E.R. Tratado de metodologia da pesquisa clínico-qualitativa: construção teórico-epistemológica, discussão comparada e aplicação nas áreas da saúde e humanas. Petrópolis, Vozes, 2003, 685. 